\title{
Exploring the impacts of climate change and mitigation policies on UK feed barley supply and implications for national and transnational food security
}

\author{
D. O. Yawson ${ }^{1}$ (D) F. A. Armah' ${ }^{2}$ M. O. Adu ${ }^{3}$
}

Received: 21 November 2019 / Accepted: 6 March 2020 / Published online: 16 March 2020

(c) Springer Nature Switzerland AG 2020

\begin{abstract}
The destabilizing impacts of climate change make mitigation measures a global imperative and urgent. The Paris Agreement and the Sustainable Development Goal 13 give fresh impetus for climate change mitigation action. However, mitigation policies can have unintended consequences for food security. The current study assessed the impacts of UK climate mitigation policies on future food penalties (using feed barley and meat) and to highlight potential tele-coupled implications for transnational food security (especially in developing economies). Total barley production for the 2030s, 2040s, and 2050s was obtained from simulated barley yields under three emissions scenarios (high, medium, and low; or HES, MES, and LES, respectively) and projected land area for barley production from the updated study on UK land use change under climate mitigation policies. Future demand for feed barley was obtained as a product of projected population and per capita demand. Feed barley equivalent meat production and demand were obtained using similar approach. The differences between future demand and supply were calculated for all combinations of climate change and land use scenarios. The results show that land area under climate mitigation scenarios would be $82-87 \%$ of the mean land area currently under barley production. Consequently, deficits in feed barley supply could range from 40 to $51 \%$ of total demand from the 2030 s to the 2050 s, while deficits in meat could be as high as $71 \%$ of total demand in the 2050s. As a result, the UK moves from its current position of net exporter of barley to a major net importer of barley or meat in the future. If current land area is maintained, maximum feed barley and meat deficits would be $44 \%$ and $65 \%$, respectively, of total demand in the 2050s. For example, based on the middle of the road land use and climate change scenarios, together with projected 90th percentile yield, feed barley deficits in the UK would be 7102, 7548, and 7963 thousand tonnes for the 2030s, 2040s and 2050s, respectively. The main sources of export of barley to the UK would have either excess domestic demand over supply or inadequate surplus to meet the fractional exports required to serve the UK deficit. Potentially increased imports by the UK from Ukraine, Germany, and France would require an adjustment in the trade flows to the current top importers from these countries as the UK's share of import would increase from less than $1 \%$ currently to $13 \%, 32 \%$, and $183 \%$, respectively. The observed magnitude of deficits highlights adverse impacts of UK land-based climate mitigation policies on its food security, with potential consequences for transnational food security, especially in developing economies that rely on the global market for feed barley or meat supply.
\end{abstract}

Keywords Climate change mitigation · Food security · Barley · Land use change · UK

D. O. Yawson, david.yawson@cavehill.uwi.edu | ${ }^{1}$ Centre for Resource Management and Environmental Studies (CERMES), The University of the West Indies, Cave Hill Campus, P.O. Box 64, Bridgetown 11000, Barbados. ${ }^{2}$ Department of Environmental Science, School of Biological Sciences, University of Cape Coast, Cape Coast, Ghana. ${ }^{3}$ Department of Crop Science, School of Agriculture, University of Cape Coast, Cape Coast, Ghana. 


\section{Introduction}

Grains constitute the largest source of energy in animal feed. Future demand for feed use of grains is projected to increase significantly in response to projected increase in demand for meat and animal products [1]. Feed use accounts for about $35 \%$ of total grains (largely coarse grains will be required for animal feed by 2050 [1, 2]. In the UK and the EU, more than half of total grains produced is used for animal feed [2,3]. Globally, barley (Hordeum vulgare L.) is the largest coarse grain used as animal feed, and feed use accounts for about $53 \%$ of total barley produced while the remainder goes into mainly malting [4]. By 2050, developing countries would account for about $56 \%$ of global feed use of coarse grains [1], indicating a potentially large increase in demand for or imports of feed barley. Kruse [5] reported that, by 2050, global aggregate barley production will have to increase by $54 \%$ (over 2000 level) to serve projected demand. In terms of area harvested and quantity produced, barley is the second most important crop in the UK and the number one crop in Scotland.

Apart from genetic and agronomic factors, climate change and land use would be the principal determinants of total barley production in the future. In the UK and other northern temperate environments, elevated atmospheric carbon dioxide in combination with moderate warming and adequate soil moisture would likely benefit cereal crops such as barley [6-8]. Such conditions would likely enhance photosynthetic capacity through efficient radiation capture and water use, and thereby increase biomass production, harvest index and drought tolerance [9-14]. In the UK and Ireland, for example, it has been shown that barley production would remain viable under climate change and yield would increase with higher carbon emission scenarios $[13,15]$. Hence, the UK could be considered a climate change beneficiary country in terms of barley production. Land use, however, could constrain total production depending on the trajectory and impacts of climate change mitigation policies on area of croplands [16].

Impact assessment of climate change on food security and adaptive responses have been focused largely on local to national scales. However, due to international trade, agricultural surpluses and deficits are increasingly becoming tele-coupled, capable of causing environmental and economic impacts not only in the countries directly involved in the trade but also across other geographical and temporal scales. Even so, risk of tele-coupled impacts of mitigation measures in a given country on other countries has yet to be factored into the discourse on climate change adaptation and justice, especially in developing countries. Food security in developing countries will be impacted by not only agro-climatic conditions but also the socio-economic and political circumstances that permit access to food on the global market $[17,18]$. This implies the need to assess and monitor the future production of crops such as barley in climate-beneficiary countries and the potential impacts on especially developing countries that depend on such crops for food security. The impacts of such future production levels on supply and prices on the global market are an important signal for food security adaptation in distal, dependent (developing) countries.

There have been reports on the potential adverse effects of climate mitigation efforts on food security (e.g. [19-22]. Climate change mitigation affects food security in two principal ways: (1) competition for resources (land, water, inputs) between food crops and mitigation plants (energy crops, forestry), and (2) competition for food crops between energy production and human consumption or feed use. A third dimension is the cost of mitigation, which could force reductions in resource allocation to food production or reduce economic welfare. A probable outcome of this competition is higher food prices (due to supply deficit) or reduced real income which would affect access to food [20]. Based on a multi-model assessment of the combined effects of climate change and mitigation policies on food security, Hasegawa et al. [23] reported that, by 2050, stringent mitigation policies, implemented evenly across all sectors and regions, would have a larger negative effect on global hunger and food consumption than the sole impacts of climate change. Low-income countries in Africa and South Asia would be severely affected. A related study indicates that, by the end of the century, land-based mitigation activities could potentially increase food prices by $110 \%$ or more over baseline (2005) value, with Africa and Asia suffering the greatest price effects [24]. Richardson et al. [18] and Krishnamurthy et al. [25] reported that current geographical distribution of vulnerabilities to food insecurity would remain unchanged or worsen under climate change unless extreme combinations of mitigation and adaptation measures are applied. While attention has been drawn to the potential impact of climate mitigation on food supply and/or prices at larger spatial scales, these reports have focused mostly on the potential impacts of increased bioenergy consumption on the risk of hunger (e.g. [19, 21, 22]). Hasegawa et al. [20] included the effect of cost of mitigation on the risk of hunger. In the current study, we assess the combined effect of climate mitigation policies (through land use change), climate change, and population change on national and transnational food security using crop- and country-specific case. We use future barley demand and supply in the UK (a strong trading nation with high self-sufficiency rate with respect to barley) as a case to demonstrate quantitatively the potential adverse impact of mitigation policies on national food 
security and the implications for tele-coupled impacts on the food security of distal economies, especially developing countries that could be considered as climate change victims.

\section{Materials and methods}

\subsection{Future barley yields and production}

\subsubsection{Climate change}

Projected climate change datasets for three emissions scenarios (low, medium and high, or LES, MES, and HES), which correspond to the $\mathrm{B} 1, \mathrm{~A} 1 \mathrm{~B}$, and $\mathrm{A} 1 \mathrm{Fl}$ emission scenarios, were obtained from the UKCP09 database. The UKCP09 is a publicly accessible online database that provides projected climate change datasets over the UK to the end of the century [26]. In the UKCP09, the future climate data have been downscaled to UK administrative regions and river basins at a grid resolution of $25 \mathrm{~km}$, and averaged over seven overlapping 30-year time slices [26]. The Weather Generator embedded in the UKCP09 applies a stochastic approach to a user-specified number of model variants that are randomly sampled from the probabilistic projections to generate statistically credible future climate variables at daily or hourly time scales [27]. The Weather Generator was used to generate daily climate data for the 2030s, 2040s, and 2050s for the fourteen UK administrative regions and for each of the three emissions scenarios. Each Weather Generator request comprised 100 random samples from 10,000 model variants run for a duration of 30 years.

It is acknowledged that the UKCP09 has been superseded by the UKCP18 (UK Climate Projections 2018), which was not published at the time of the current study. Principally, the UKCP18 has five emission scenarios (RCP2.6, RCP4.5, RCP6.0, RCP8.5, and SRES A1B). While the use of the RCP emission scenarios represents an inclusion of a wider range of future atmospheric $\mathrm{CO}_{2}$ concentrations and associated climate forcing over the SRES used in UKCP09, large overlap of projected ranges of several climate metrics exists between UKCP18 and UKCP09 [28]. For example, the range of future climate change forcings of RCP4.5 to RCP8.5 is similar to the scenarios of the UKCP09 [28]. The explicit inclusion of the SRES A1B in the UKCP18 permits comparison of UKCP19 and UKCP09 to obtain the effects of the improvement in methodology and input data. Such a comparison for South East England, for example, shows that there is not much difference in summer temperatures between the UKCP18 and UKCP09 even though the difference is slightly larger for winter temperatures [28]. With precipitation, the UKCP18 tends to show either larger reductions or smaller increases over baseline values compared to UKCP09. Generally, the two datasets show considerable similarities over land [28]. These notwithstanding, using UKCP18 instead of UKCP09 could alter the results as reported in the current study.

Soil data were obtained from the Crop Growth Monitoring System (CGMS) database in the new Soil Information System (SINFO), which is part of the agricultural monitoring and yield forecasting programme of the European Union [29]. After download, the SINFO data were imported and processed in ArcGIS 9.1 (ESRI ${ }^{\mathrm{TM}}$, Redlands, CA, USA). The UK was clipped and attribute tables of soil mapping units (SMU) and soil typological units (STU-describing soil properties) were joined using common fields. The resulting join table was in turn joined to the soil physical group attribute table to obtain a single attribute table for the soil polygons. Weighted averages of soil hydraulic properties were then obtained at regional level. It is noteworthy that drainage characteristics such as drainage coefficient, saturated hydraulic conductivity, and curve number for surface runoff (not available from the SINFO data) were generated in the AquaCrop model based on the input values of saturated water content, field capacity, and permanent wilting point which were obtained from the SINFO data. The soil hydraulic properties input data required by AquaCrop and were obtained from the SINFO are presented in "Appendix 1".

The crop data were based on the genotype Westminster, which was grown in the field at The James Hutton Institute (Invergowrie, Dundee, UK) and used in the initial calibration and validation of the AquaCrop model. During this study, the genotype Westminster was on the HGCA (Home-Grown Cereals Authority, UK) Recommended List as a high-yielding genotype, widely grown both as spring and winter barley and for feed and malt. The AquaCrop model which was used in the current study simulates the responses of crop biomass production and yield in response to mainly soil and climatic conditions. The detailed description of the model's architecture and algorithms can be found in Raes et al. [30] and the conceptual framework, underlying principles and distinctive components and features can be found in Steduto et al. [31]. For the calibration, the difference between observed and predicted yield was 0.14 tons $\mathrm{ha}^{-1}$ while the difference at validation using 2 years data points were 0.91 and 1.73 tons $\mathrm{ha}^{-1}$. The overall calibration-validation root-meansquare error (RMSE) for genotype Westminster was $8.10 \%$ (see [32] for further details). 
Detailed description of the simulation under projected climate change can be found in Yawson et al. [15]. In summary, the search for future sowing dates for UK regions was based on the HGCA recommended sowing window (from late January to end of February in the south and east of England, and from late February to the end of March in Scotland). Because of potential quality and yield penalties outside of this window, the search for appropriate sowing dates in AquaCrop was restricted to the HGCA recommendation. To this end, the method of Mainuddin et al. [33] was followed to obtain sowing dates. Thus, sowing date for each region was obtained by forcing AquaCrop to the 1990 spring barley yield for that region by varying only sowing date until the simulated yield approximated the observed yield. The first sowing date that gave the closest match between observed and simulated yields was taken as the sowing date as was reported. For 1990, the differences between the observed and simulated yields ranged from -0.14 to 0.59 tons $\mathrm{ha}^{-1}$. The obtained sowing dates were applied to simulate and compare the yields from 1980 to 1989 in order to assess the reliability of the sowing dates using the RMSE $[15,33]$. The RMSE values for the 14 UK regions ranged from 0.44 (for East of England) to 1.15 tons ha $^{-1}$ (for Wales), and 0.35 tons ha $^{-1}$ for the UK [15]. Subsequently, the projected climate data, together with the soil, crop, and atmospheric $\mathrm{CO}_{2}$ concentration data for the respective emission scenarios and time slices were used to simulate future spring barley yields using the sowing dates obtained for the respective regions. The simulations were done under rainfed conditions, based on thermal time, and assuming no fertility stress. The main AquaCrop parameterization information is provided in "Appendix 2". The regional yields and their associated statistics are reported in Yawson et al. [15]. The regional yields were averaged to obtain the UK national yield data used in the current study. Further information can be obtained in Yawson [32].

\subsubsection{Climate change mitigation and land use}

Future cropland data were obtained from the study report Inventory and Projections of UK Emissions by Sources and Removals by Sinks due to Land Use, Land Use Change and Forestry (LULUCF) by Thomson et al. [34]. This is a revised or updated study on land use responses to climate mitigation policies and aspirations in the UK. The UK Climate Change Act [35] targets $80 \%$ emission reduction (relative to the 1990 baseline) by 2050. For purposes of carbon budgets under the UK Climate Change Act [35], European Union Monitoring Mechanism and the UN Framework Convention on Climate Change (UNFCCC), it is mandatory for the UK to report projections for the Land Use, Land Use Change and Forestry (LULUCF) sector [36]. The UK Climate
Change Act specifically requires periodic reports on progress towards the emission target and review of strategies and policies to remain on track as new inventory data become available. It is in this context that the studies by Thomson et al. $[34,36]$ were conducted for the UK Government. The latest report on projected emissions and removals of greenhouse gases from the LULUCF sector [34] differs from the 2013 report in terms of scenarios, data currency, and methodological considerations [34]. In the updated report, three policy scenarios (Central, Low, and Stretch) and two baseline scenarios were developed and the projected cropland areas were different from those in the previous report. It is important to note that these policy scenarios were jointly developed by the Department of Business, Energy and Industrial Strategy (BEIS, formerly the Department of Energy and Climate Change), the Department for Environment, Food and Rural Affairs (Defra), and the Forestry Commission, in consultation with the UK devolved administrations and incorporate current land use policies and aspirations [34]. Details of the scenarios are available in Thomson et al. [34]. In summary, the Baseline 1 scenario (BL1) maintains the 2000-2009 average activity rates (based on climate change-related and forestry policies prevalent in July 2009) to the 2050s. The Baseline 2 (BL2) is similar to BL1 except that forest planting rates decline to a low level after 2015 as grant-aided planting remains constant at 2009 level. In the Central Scenario, policies and funding prevalent in 2014 remain unchanged to 2050 for non-forest activities. However, the 2014 afforestation rates are maintained to 2021 and reduced thereafter to the levels in BL2. The Low Scenario projects forward the climate change mitigation policy aspirations for the UK Devolved Administrations beyond 2021. Finally, the Stretch Scenario is an ambitious scenario which captures climate change mitigation actions exceeding current policy aspirations or funding. The results were provided for England, Northern Ireland, Scotland, and Wales, and national (UK) average. This updated study has implications for the quantity of food that can be produced due to land use changes.

Projected areas of UK (national) croplands for the 2030s, 2040s, and 2050s, due to land use changes in response to emission targets or climate mitigation policies are obtained from Annex 2 [34] and the corresponding areas of barley were obtained as a proportion of the croplands. To achieve this, average area of barley for the period 2000-2012 was calculated as a percentage of the mean of total croplands for the same period. This proportion (16.36\%) was applied to the areas of croplands obtained from Thomson et al. [34] to obtain future areas of barley for the respective climate mitigation scenarios and time slices. In addition, the actual mean value of area under barley cultivation for the period 2000-2012 (1026 thousand 
ha) was used to represent land area under current conditions or a business as usual (BAU) scenario, which remains unchanged from the 2030s to the 2050s.

Unlike the previous study [16], the current study uses all the land use scenarios from Thomson et al. [34] and does not incorporate crop-specific land use changes in response to non-policy factors. Future total barley production (supply) was obtained as the product of simulated yield [15] and projected land area of barley for the respective time slices, emissions and land use scenarios. In the current study, the 90th and 50th percentile yields were used to represent the optimistic situation (highest yields) and to make the current paper comparable to the previous paper based on the mean or median (normal) yields.

\subsection{Future demand, balances and implications for national and transnational food security}

Future demand of feed barley and/or feed barley equivalent meat demand (FBEM) and differences between demand and supply were estimated as described previously [16]. In summary, the projected population from the constant fertility scenario was used in combination with projected per capita feed barley or meat demand to obtain future total demand. Projected per capita demand for meat and feed grains were obtained from the Comprehensive Assessment of Water Management in Agriculture [37] as described in Yawson et al. [16]. The IWMI [37] study was based on assumptions of changes in population, dietary requirements and composition (or preferences), incomes, prices of commodities and inputs, and urbanization. It explicitly provided projected demand for feed grain and meat and was therefore more suited to the purpose of the current study unlike other similar reports such as the FAO projections [1], The Global Harvest Initiative Report [5], and Tilman et al. [38].

A causal loop analysis, a component of systems dynamics analysis, was used to explore the implications of the future barley or FBEM balances in the UK on national food security and potential tele-coupled impacts on the food security of distal economies through cascading effects on the regional or global food market. Causal loop diagram (CLD) analysis was the main tool used to conceptualize the national food security risk and then for exploring the broader implications for transnational food security risks (Fig. 4). The CLD approach helps provide nuanced understanding of the structure (system components, connections and interactions) and overall behaviour of a system or problem by making explicit the causal-feedback relationships between components and thereby helps address the problem by evaluating outcomes $[39,40]$. The CLD, a graphical depiction of the causal-feedback relationships arising from the behaviour and interaction of system components or other exogenous factors relevant to the system, is the first major stage of constructing a system dynamics model.

To provide numerical support or a perspective to what the CLD portrays, an analysis of future barley supplies from the main trading partners of the UK, relative to the UK deficits under the medium emissions climate change scenario (MES) and the Central climate mitigation land use scenario in the 2050s was done. From the FAOSTAT database, eight countries accounted for $95 \%$ of total UK barley import. These countries were therefore selected to represent the potential sources of UK barley imports in the future. Taking these eight countries as $100 \%$, their respective percentage shares in total UK barley imports were calculated: Ireland (47\%), France (17\%), Germany (13\%), Ukraine (7\%), Spain (5\%), Denmark (4\%), Sweden (4\%), and Italy (3\%). Subsequently, the national yields of these countries, together with UK yields, for the period 1998-2017 were retrieved from the FAOSTAT database. These were used to develop regression relationships to predict future yields in the trading partner countries but this proved unreliable. As a result, the mean of the yearly difference between each country's yield and the UK yield for the period under consideration $(M)$ was calculated and added to 90 th or 50 th percentile UK yield under the MES to obtain an estimated yield for the partner country in the 2050s:

$M= \pm \sum_{i=1}^{n} \frac{Y P_{i}-Y U_{i}}{n}+Y U_{M E S, 2050}$

where $M=$ mean of the differences in yields for the period under consideration; $\mathrm{n}$ is the number of observations or years; $Y P_{i}$ is the yield in partner country $i$ for year $i ; Y U_{i}$ is the UK yield for year $i$. $Y U_{M E S, 2050}$ is the UK yield under the medium emission scenario in the 2050s.

The estimated yields were then multiplied with the mean land area of barley for the same period to estimate the future production (i.e. assuming the partner countries would maintain their current land area to the 2050s). From the food balance sheets of the partner countries for 2016, the per capita supply of barley was obtained from the food balance sheet as the ratio of domestic supply to population. This per capita supply was then used as the status quo demand and multiplied by the projected population of the respective partner country [41] to obtain future demand. The estimated future demand was then subtracted from the future production to obtain the 'exportable fraction' (surplus over supply for domestic use or demand). Because Ireland, France, Germany and Ukraine accounted for $84 \%$ of total UK barley import, the subsequent analysis was based on these countries. For these countries, the difference between the future exportable fraction and current total export was calculated. The main export destinations 
of barley from these four countries were retrieved from the FAOSTAT for the year 2016. The percentage share of the top 20 importing countries from the total export of these four countries was calculated. The resulting value was used to calculate the share of export to the top 20 countries from the future exportable fraction. The remaining quantity of barley (residual) for export to the rest of the world (including the UK where applicable) was then obtained as the difference between the exportable fraction and the quantity to be exported to the top 20 importing countries.

\section{Results}

\subsection{Future barley production}

Projected barley yields were highest under the high emissions scenario (HES) and in the 2050s and lowest under the low emissions scenario (LES) in the 2030s (Fig. 1).
Generally, both the 90th and 50th percentile yields increased across the time slices. The highest 90th and 50th percentile yields were 8.27 and 7.87 tonnes $\mathrm{ha}^{-1}$, respectively, under the HES in the 2050s. The lowest yield value was 6.01 tonnes ha ${ }^{-1}$ (the 50th percentile yield under the LES) in the 2030s.

The total area of land for barley under the business as usual (BAU) or current condition was 1026 thousand ha. For all climate mitigation scenarios and time slices, the projected land area was lower than the current land area under barley production (the BAU). The largest land area (approximately 893 thousand ha under the stretch scenario in the 2050s) was $87 \%$ of the land area under the $\mathrm{BAU}$, while the lowest land area (approximately 840 thousand ha under the BL scenarios in the 2030s) was about $82 \%$ of the BAU (Fig. 2). The projected land areas under the low and central scenarios were similar, and the value in the 2050 s ( 884 thousand ha) was $86 \%$ of the BAU. Because
Fig. 1 Projected barley grain yield for the low, medium, high emission scenarios (LES, MES, and $H E S$, respectively) in the 2030s, 2040s, and the 2050s
Fig. 2 Projected land area for barley in 2030, 2040, and 2050 based on climate mitigation policies [34]. The total area of barley under the BAU remains constant at 1026 thousand ha from 2030 to 2050
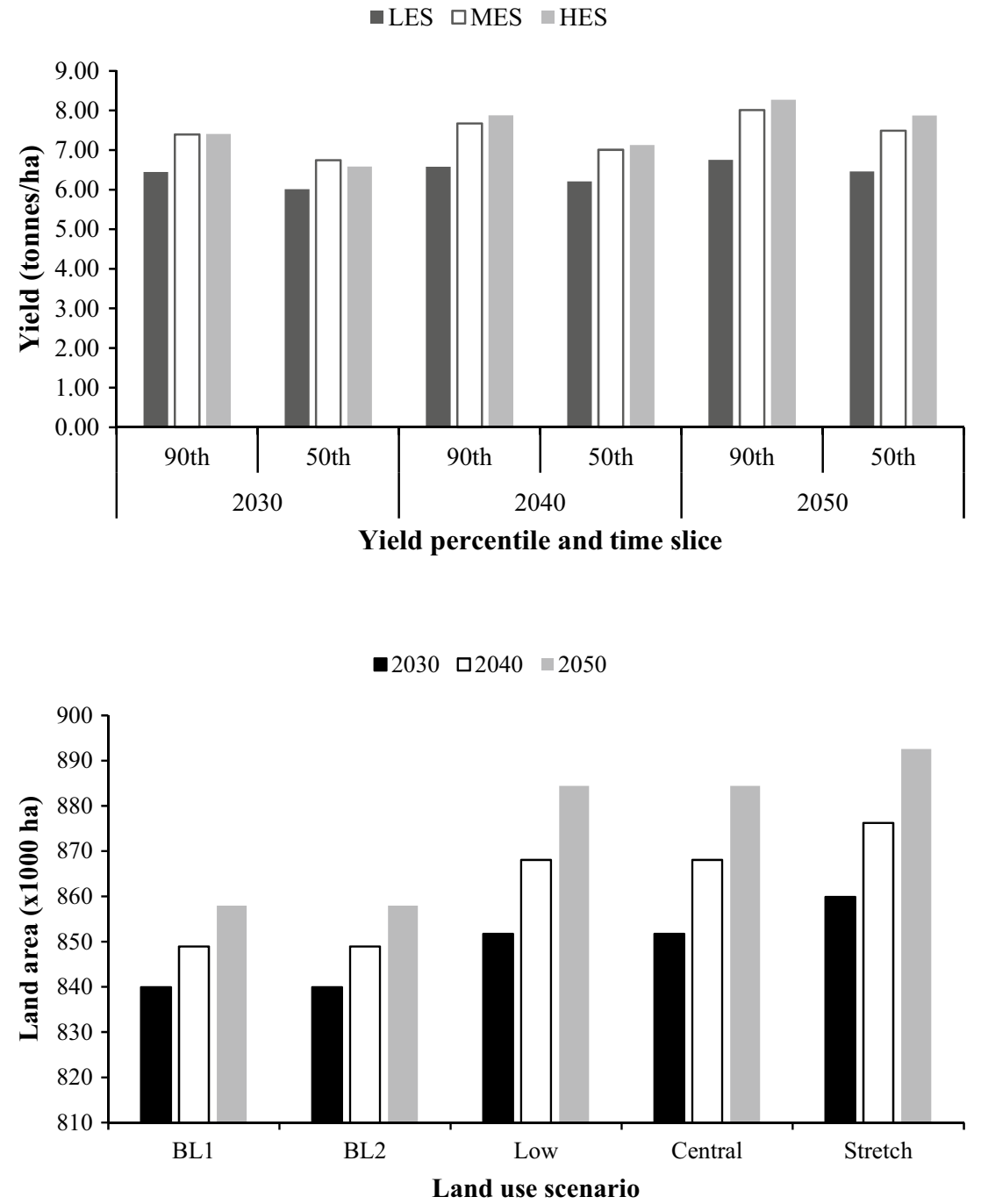
Table 1 Total barley production (thousand tonnes) under projected climate and land use change

\begin{tabular}{|c|c|c|c|c|c|c|}
\hline $\begin{array}{l}\text { Emission } \\
\text { scenario }\end{array}$ & Yield percentile & BAU & $B L$ & Low & Central & Stretch \\
\hline \multicolumn{7}{|l|}{2030} \\
\hline \multirow[t]{2}{*}{ LES } & 90th & 6614.27 & 5414.69 & 5490.63 & 5490.63 & 5543.36 \\
\hline & 50th & 6167.93 & 5049.30 & 5120.11 & 5120.11 & 5169.28 \\
\hline \multirow[t]{2}{*}{ MES } & 90th & 7584.74 & 6209.15 & 6296.23 & 6296.23 & 6356.70 \\
\hline & 50th & 6917.97 & 5663.31 & 5742.73 & 5742.73 & 5797.89 \\
\hline \multirow[t]{2}{*}{ HES } & 90th & 7602.66 & 6223.83 & 6311.11 & 6311.11 & 6371.72 \\
\hline & 50th & 6752.27 & 5527.66 & 5605.18 & 5605.18 & 5659.02 \\
\hline \multicolumn{7}{|l|}{2040} \\
\hline \multirow[t]{2}{*}{ LES } & 90th & 6748.52 & 5583.77 & 5709.68 & 5709.68 & 5763.48 \\
\hline & 50th & 6369.71 & 5270.35 & 5389.18 & 5389.18 & 5439.97 \\
\hline \multirow[t]{2}{*}{ MES } & 90th & 7874.1 & 6515.09 & 6661.99 & 6661.99 & 6724.77 \\
\hline & 50th & 7188.56 & 5947.87 & 6081.98 & 6081.98 & 6139.29 \\
\hline \multirow[t]{2}{*}{ HES } & 90th & 8082.00 & 6687.11 & 6837.89 & 6837.89 & 6902.33 \\
\hline & 50th & 7315.12 & 6052.59 & 6189.06 & 6189.06 & 6247.38 \\
\hline \multicolumn{7}{|l|}{2050} \\
\hline \multirow[t]{2}{*}{ LES } & 90th & 6928.15 & 5793.16 & 5972.13 & 5972.13 & 6027.36 \\
\hline & 50th & 6627.28 & 5541.58 & 5712.77 & 5712.77 & 5765.61 \\
\hline \multirow[t]{2}{*}{ MES } & 90th & 8215.91 & 6869.97 & 7082.20 & 7082.20 & 7147.70 \\
\hline & 50th & 7685.72 & 6426.63 & 6625.16 & 6625.16 & 6686.44 \\
\hline \multirow[t]{2}{*}{ HES } & 90th & 8486.22 & 7095.99 & 7315.20 & 7315.20 & 7382.86 \\
\hline & 50th & 8079.69 & 6756.06 & 6964.77 & 6964.77 & 7029.18 \\
\hline
\end{tabular}

the cropland areas for the BL1 and BL2 were the same, we simply use one to represent the baseline $(B L)$ henceforth.

Future total barley production for all climate and land use change scenarios across the time slices are presented in Table 1. At the 90th percentile yield, total barley production under the land-based climate mitigation policies ranged from 5415 (LES, 2030s) to 7383 thousand tonnes (HES, 2050s), which were approximately $82-87 \%$ of the production under the BAU. For the 50th percentile yield, total barley production ranged from 5049 (LES, 2030s) to 7029 thousand tonnes (HES, 2050s). For these scenarios, highest production occurred under the Stretch scenario while the lowest occurred under the baseline $(B L)$ scenario in correspondence with differences in land area. As yields were highest in the 2050s, total production was highest in the 2050s. For the BAU and BL, the total production under the LES did not differ substantially between the 2030s and the 2040s but that is not the case for the other land use and emissions scenarios.

Total amount of feed barley that would be available from total domestic barley production (assuming current proportionate distribution to end uses remains unchanged) is presented in Table 2. Since this is a constant proportion of the total production values, the pattern is similar to the total production. That is, total amounts of feed barley from domestic production under the climate mitigation land use scenarios are lower than the corresponding values under the BAU. If current land area under barley cultivation (BAU) is continued, then total feed barley supplies from domestic production at 90th percentile yield would range from 4055 (LES, 2030s) to 5202 thousand tonnes (HES, 2050s), which would be 18-13\% higher than the corresponding supplies under the climate mitigation land use scenarios.

\subsection{Future barley demand and deficits}

Projected UK population for the 2030s, 2040s, 2050s were $71.9,76.1$, and 80.3 million. The corresponding demand ranged from 10,962 , to 12,304 thousand tonnes for feed barley, and 2657-2999 thousand tonnes for feed barley equivalent meat (Fig. 3). At the 90th percentile yield, the least and largest deficits in feed barley under the current land area (the BAU) ranged from 6302 (HES) in the 2030s to 8057 thousand tonnes (LES) in the 2050s (Table 3). These represented about $31 \%$ and $40 \%$ deficits, respectively, in total demand in the 2030 s or $31 \%$ and $44 \%$, respectively, of total demand in the 2050s. Under the climate mitigation land use scenarios, the least and largest deficits were $42 \%$ (Stretch, HES) and 51\% (BL, LES), respectively, of total demand in the 2030s. The corresponding values in the 2050s were $40 \%$ and $53 \%$, respectively. Using the Central scenario of the climate mitigation policies, the middle of the road emissions scenario (MES), and the 90th percentile 
Table 2 Proportionate feed barley supply (thousand tonnes) from domestic production

\begin{tabular}{|c|c|c|c|c|c|c|}
\hline $\begin{array}{l}\text { Emission } \\
\text { scenario }\end{array}$ & Yield percentile & BAU & $B L$ & Low & Central & Stretch \\
\hline \multicolumn{7}{|l|}{2030} \\
\hline \multirow[t]{2}{*}{ LES } & 90th & 4054.55 & 3319.21 & 3365.76 & 3365.76 & 3398.08 \\
\hline & 50 th & 3780.94 & 3095.22 & 3138.63 & 3138.63 & 3168.77 \\
\hline \multirow[t]{2}{*}{ MES } & 90th & 4649.44 & 3806.21 & 3859.59 & 3859.59 & 3896.66 \\
\hline & 50th & 4240.71 & 3471.61 & 3520.30 & 3520.30 & 3554.12 \\
\hline \multirow[t]{2}{*}{ HES } & 90th & 4660.43 & 3815.21 & 3868.71 & 3868.71 & 3905.87 \\
\hline & 50th & 4139.14 & 3388.46 & 3435.98 & 3435.98 & 3468.98 \\
\hline \multicolumn{7}{|l|}{2040} \\
\hline \multirow[t]{2}{*}{ LES } & 90th & 4136.84 & 3422.85 & 3500.03 & 3500.03 & 3533.01 \\
\hline & 50th & 3904.63 & 3230.73 & 3303.57 & 3303.57 & 3334.70 \\
\hline \multirow[t]{2}{*}{ MES } & 90th & 4826.82 & 3993.75 & 4083.80 & 4083.80 & 4122.28 \\
\hline & 50th & 4406.59 & 3646.05 & 3728.26 & 3728.26 & 3763.39 \\
\hline \multirow[t]{2}{*}{ HES } & 90th & 4954.27 & 4099.20 & 4191.63 & 4191.63 & 4231.13 \\
\hline & 50 th & 4484.17 & 3710.24 & 3793.89 & 3793.89 & 3829.64 \\
\hline \multicolumn{7}{|l|}{2050} \\
\hline \multirow[t]{2}{*}{ LES } & 90th & 4246.96 & 3551.21 & 3660.92 & 3660.92 & 3694.77 \\
\hline & 50 th & 4062.52 & 3396.99 & 3501.93 & 3501.93 & 3534.32 \\
\hline \multirow[t]{2}{*}{ MES } & 90th & 5036.36 & 4211.29 & 4341.39 & 4341.39 & 4381.54 \\
\hline & 50th & 4711.35 & 3939.52 & 4061.23 & 4061.23 & 4098.79 \\
\hline \multirow[t]{2}{*}{ HES } & 90th & 5202.05 & 4349.84 & 4484.22 & 4484.22 & 4525.69 \\
\hline & 50th & 4952.85 & 4141.46 & 4269.40 & 4269.40 & 4308.89 \\
\hline
\end{tabular}

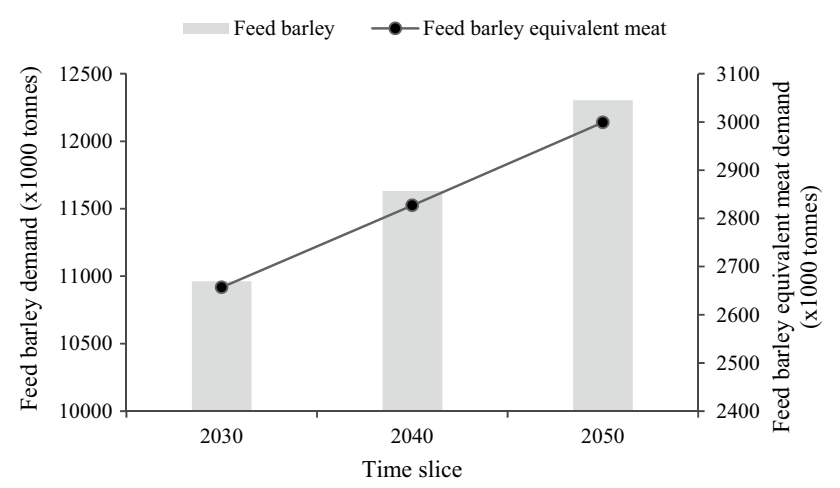

Fig. 3 Projected feed barley and feed barley equivalent meat demand

yield, the projected deficits in feed barley supply would be 7102,7548 , and 7963 thousand tonnes for the 2030s, 2040 s and 2050s, respectively. The deficits could far exceed 8000 thousand tonnes for the 50th percentile yield and the climate mitigation land use scenarios under the LES in the 2040s and 2050s and could be as high as 8907 thousand tonnes. The deficits were highest under the BL for all emissions scenarios and time slices, and at both the 90th and 50th percentile yields.

The projected deficits in feed barley equivalent meat (FBEM) demand are expectedly larger under the climate mitigation land use scenarios than under the current land area (the BAU). At the 90th percentile yield, the FBEM deficits would range from 1527 thousand tonnes (HES, 2030s) to 1964 thousand tonnes (LES, 2050s) for the BAU (Table 4), representing $57 \%$ and $65 \%$, respectively, of total demand in these two time slices. With the climate mitigation scenarios, the FBEM deficits ranged from 1710 to 2133 thousand tonnes from the 2030s to the 2050s. The range of the deficits represented $64 \%$ and $71 \%$, respectively, of total demand from the 2030s to the 2050s. Using the Central scenario, the MES and the 90th percentile yield, the FBEM deficits would range from 1722 (2030s) to 1941 thousand tonnes in the 2050s. Again, these deficits increase substantially under the 50th percentile yield in accordance with the difference between the 90th and 50th percentile yields.

\subsection{Implications for national and transnational food security}

Causal loop diagrams (CLD) are graphical representations used to logically explore the causal-feedback relationships between components of complex systems. It is extensively used in systems dynamics analysis and modelling. This simplified CLD (Fig. 4) shows the most relevant feedback relationships between UK barley production, UK demand and supply of feed barley or FBEM, and the impacts on 
Table 3 Projected deficits in feed barley (thousand tonnes) based on domestic feed barley supply

\begin{tabular}{|c|c|c|c|c|c|c|}
\hline $\begin{array}{l}\text { Emission } \\
\text { scenario }\end{array}$ & Yield percentile & BAU & $B L$ & Low & Central & Stretch \\
\hline \multicolumn{7}{|l|}{2030} \\
\hline \multirow[t]{2}{*}{ LES } & 90th & 6907.45 & 7642.79 & 7596.25 & 7596.25 & 7563.92 \\
\hline & 50th & 7181.06 & 7866.78 & 7823.37 & 7823.37 & 7793.23 \\
\hline \multirow[t]{2}{*}{ MES } & 90th & 6312.56 & 7155.79 & 7102.41 & 7102.41 & 7065.34 \\
\hline & 50th & 6721.29 & 7490.39 & 7441.7 & 7441.7 & 7407.89 \\
\hline \multirow[t]{2}{*}{ HES } & 90th & 6301.57 & 7146.80 & 7093.29 & 7093.29 & 7056.13 \\
\hline & 50th & 6822.86 & 7573.54 & 7526.02 & 7526.02 & 7493.02 \\
\hline \multicolumn{7}{|l|}{2040} \\
\hline \multirow[t]{2}{*}{ LES } & 90th & 7495.16 & 8209.15 & 8131.97 & 8131.97 & 8098.99 \\
\hline & 50th & 7727.37 & 8401.28 & 8328.43 & 8328.43 & 8297.30 \\
\hline \multirow[t]{2}{*}{ MES } & 90th & 6805.18 & 7638.25 & 7548.2 & 7548.2 & 7509.72 \\
\hline & 50th & 7225.41 & 7985.96 & 7903.75 & 7903.75 & 7868.61 \\
\hline \multirow[t]{2}{*}{ HES } & 90th & 6677.73 & 7532.80 & 7440.37 & 7440.37 & 7400.87 \\
\hline & 50 th & 7147.83 & 7921.76 & 7838.11 & 7838.11 & 7802.36 \\
\hline \multicolumn{7}{|l|}{2050} \\
\hline \multirow[t]{2}{*}{ LES } & 90th & 8057.05 & 8752.79 & 8643.09 & 8643.09 & 8609.23 \\
\hline & 50 th & 8241.48 & 8907.01 & 8802.07 & 8802.07 & 8769.68 \\
\hline \multirow[t]{2}{*}{ MES } & 90th & 7267.64 & 8092.71 & 7962.61 & 7962.61 & 7922.46 \\
\hline & 50th & 7592.65 & 8364.48 & 8242.78 & 8242.78 & 8205.21 \\
\hline \multirow[t]{2}{*}{ HES } & 90th & 7101.95 & 7954.16 & 7819.78 & 7819.78 & 7778.31 \\
\hline & 50th & 7351.15 & 8162.54 & 8034.60 & 8034.60 & 7995.11 \\
\hline
\end{tabular}

Table 4 Projected deficits in feed barley equivalent meat (FBEM, thousand tonnes) due to deficits in domestic feed barley supply

\begin{tabular}{|c|c|c|c|c|c|c|}
\hline $\begin{array}{l}\text { Emission } \\
\text { scenario }\end{array}$ & Yield percentile & BAU & $B L$ & Low & Central & Stretch \\
\hline \multicolumn{7}{|l|}{2030} \\
\hline \multirow[t]{2}{*}{ LES } & 90th & 1674.25 & 1852.48 & 1841.2 & 1841.2 & 1833.36 \\
\hline & 50 th & 1740.57 & 1906.77 & 1896.25 & 1896.25 & 1888.94 \\
\hline \multirow[t]{2}{*}{ MES } & 90th & 1530.05 & 1734.44 & 1721.5 & 1721.5 & 1712.52 \\
\hline & 50th & 1629.12 & 1815.54 & 1803.74 & 1803.74 & 1795.55 \\
\hline \multirow[t]{2}{*}{ HES } & 90th & 1527.39 & 1732.26 & 1719.29 & 1719.29 & 1710.29 \\
\hline & 50 th & 1653.74 & 1835.7 & 1824.18 & 1824.18 & 1816.18 \\
\hline \multicolumn{7}{|l|}{2040} \\
\hline \multirow[t]{2}{*}{ LES } & 90th & 1821.6 & 1995.12 & 1976.36 & 1976.36 & 1968.35 \\
\hline & 50 th & 1878.03 & 2041.82 & 2024.11 & 2024.11 & 2016.55 \\
\hline \multirow[t]{2}{*}{ MES } & 90th & 1653.91 & 1856.37 & 1834.49 & 1834.49 & 1825.13 \\
\hline & 50th & 1756.04 & 1940.88 & 1920.9 & 1920.9 & 1912.36 \\
\hline \multirow[t]{2}{*}{ HES } & 90th & 1622.93 & 1830.74 & 1808.28 & 1808.28 & 1798.68 \\
\hline & 50th & 1737.18 & 1925.28 & 1904.95 & 1904.95 & 1896.26 \\
\hline \multicolumn{7}{|l|}{2050} \\
\hline \multirow[t]{2}{*}{ LES } & 90th & 1963.84 & 2133.42 & 2106.68 & 2106.68 & 2098.43 \\
\hline & 50th & 2008.79 & 2171.01 & 2145.43 & 2145.43 & 2137.54 \\
\hline \multirow[t]{2}{*}{ MES } & 90th & 1771.43 & 1972.53 & 1940.82 & 1940.82 & 1931.04 \\
\hline & 50th & 1850.65 & 2038.77 & 2009.11 & 2009.11 & 1999.95 \\
\hline \multirow[t]{2}{*}{ HES } & 90th & 1731.04 & 1938.76 & 1906.01 & 1906.01 & 1895.9 \\
\hline & 50th & 1791.78 & 1989.55 & 1958.37 & 1958.37 & 1948.74 \\
\hline
\end{tabular}




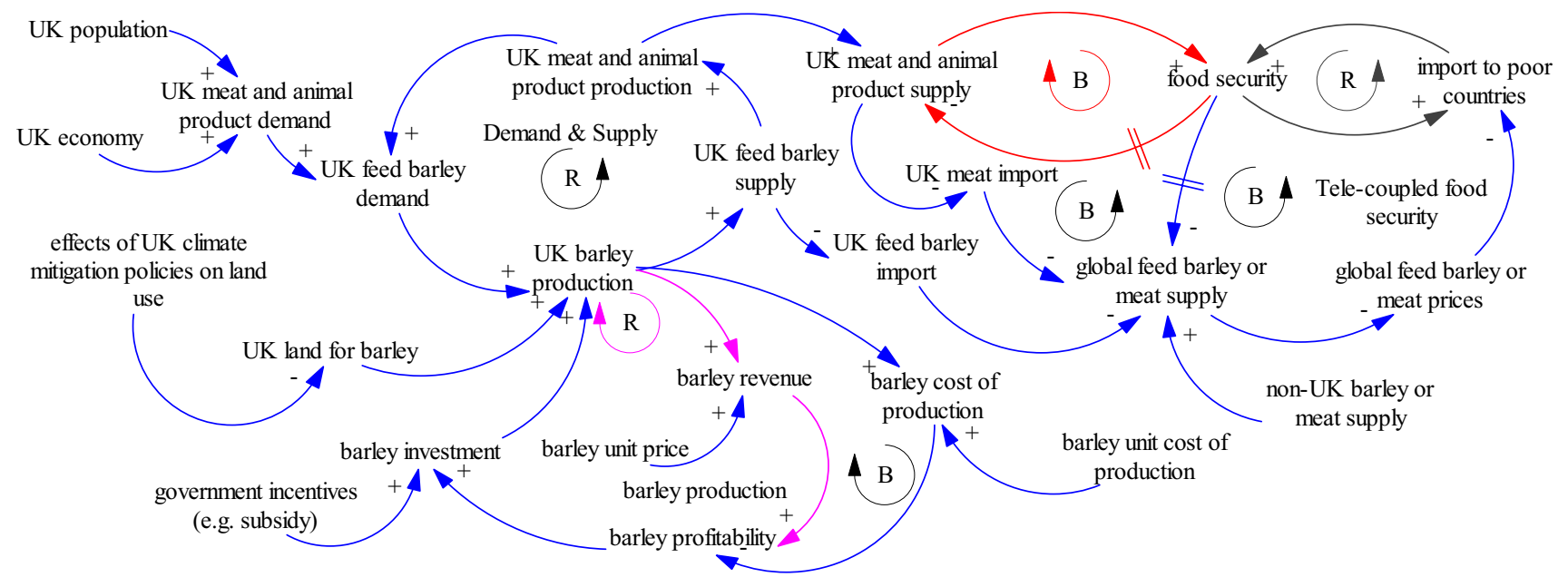

Fig. 4 Causal loop diagram of tele-coupled impacts of UK feed barley deficits on the food security of distal, poor economies

national and transnational food security. In the CLD, a negative sign indicates opposite direction (i.e. an increase in one variable results in a corresponding decrease in the variable to which it is linked and vice versa). Conversely, a positive sign indicates change in the same direction (i.e. a decrease or increase in one variable results in a corresponding decrease or increase, respectively, in the variable to which it is linked). In the CLD, there are three reinforcing feedback loops (indicated with R) and four balancing loops (indicated with B).

In the demand and supply loop or sub-system (upper left), increase in population and economic welfare (exogenous factors) leads to increase in demand for meat and animal products, which triggers increased demand for feed barley. In response, barley production increases to match the demand, which leads to increased feed barley supply and therefore meat production. Increased barley production leads to increased barley revenue, profitability and investment in barley production (second reinforcing loop in the barley production sub-system, lower left). These are positive self-reinforcing loops. However, barley production is not only driven by demand and profitability, but also subject to land area allocated to barley production in response to climate mitigation policies and the unit cost of barley production (exogenous factors which can constrain total barley production). This creates a selfbalancing loop (lower left) where growth or expansion is moderated and checked from within the loop, resulting in an innately stable sub-system. This loop provides a check or limit on total barley production regardless of the magnitude of demand. Thus, the barley production sub-system is controlled by two main loops: (1) a positive self-reinforcing loop based on incentives, profitability and investments, and (2) a balancing loop driven by land area and cost of production. On the righthand side of the CLD, feed barley or meat supply (availability) on the global market depends on the magnitude of UK feed barley or meat imports (which in turn depend on the scale of deficits in domestic supply from domestic production) and non-UK supply. Increased UK imports lowers availability on the global market, which results in increased prices of feed barley or meat, then to reduced imports to especially poor countries, with the ultimate result of reduced food security. Here, the feedback relationships between food security and global supply or availability of feed barley or meat is controlled by two balancing loops, one related to the magnitude of UK imports, and the other related to global prices and transnational imports to especially poor economies (tele-coupled impacts loop). Food security itself comprises the UK national loop (balancing loop with a delayed feedback effect on UK national feed barley and meat supply), and the transnational loop (positive selfreinforcing loop, respectively).

The analysis of the UK's barley imports showed that the UK is currently a small importer. From the top four sources of import, the UK accounted for 29,593 tonnes (approximately 99.96\%) of export from Ireland, with Sweden and South Africa accounting for only 7 and 5 tonnes, respectively (approximately $0.02 \%$ each, Fig. 5). The UK ranked 37 th importer, accounting for $0.01 \%$ of export from France, 19th (or $0.01 \%$ ) of export from Germany, and 28th (or $0.07 \%$ ) for Ukraine. The top 20 importers from France, Germany, and Ukraine accounted for $98.5 \%, 99.9 \%$, and $98.4 \%$, respectively, while the top 20 importers from the UK accounted for approximately $100 \%$ of the UK export (data not shown). About $50 \%$ of the top 20 UK importers were European countries and about 25\% were North Africa Middle East (MENA) countries (Fig. 6). In 2016, the total export by the UK was $1,757,080$ tonnes while the total import was 107,290 tonnes (approximately $6 \%$ of export), 

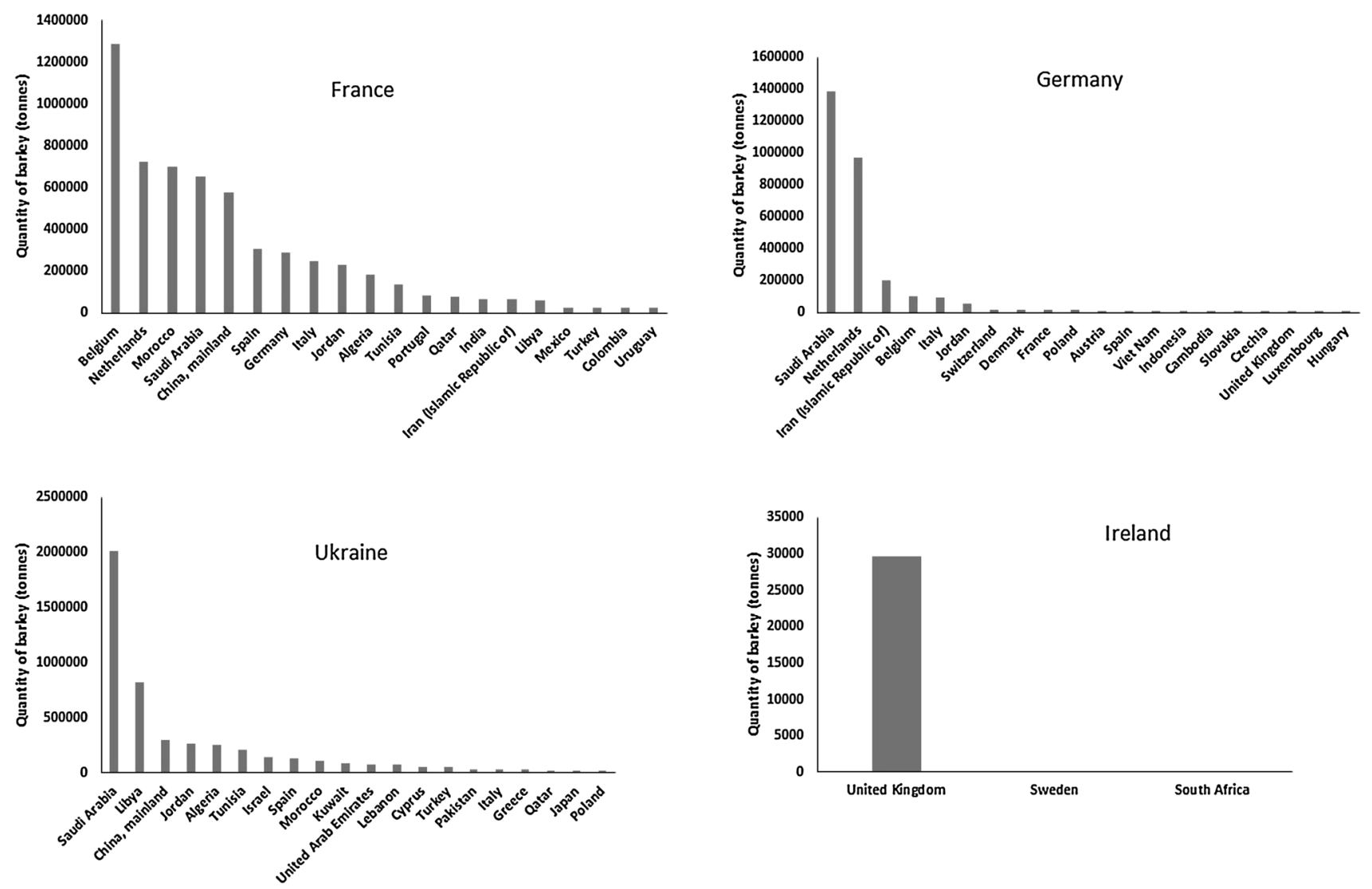

Fig. 5 Current top 20 importers of barley from the main sources of barley imports to the UK

Fig. 6 Current top 20 importers of barley from the UK

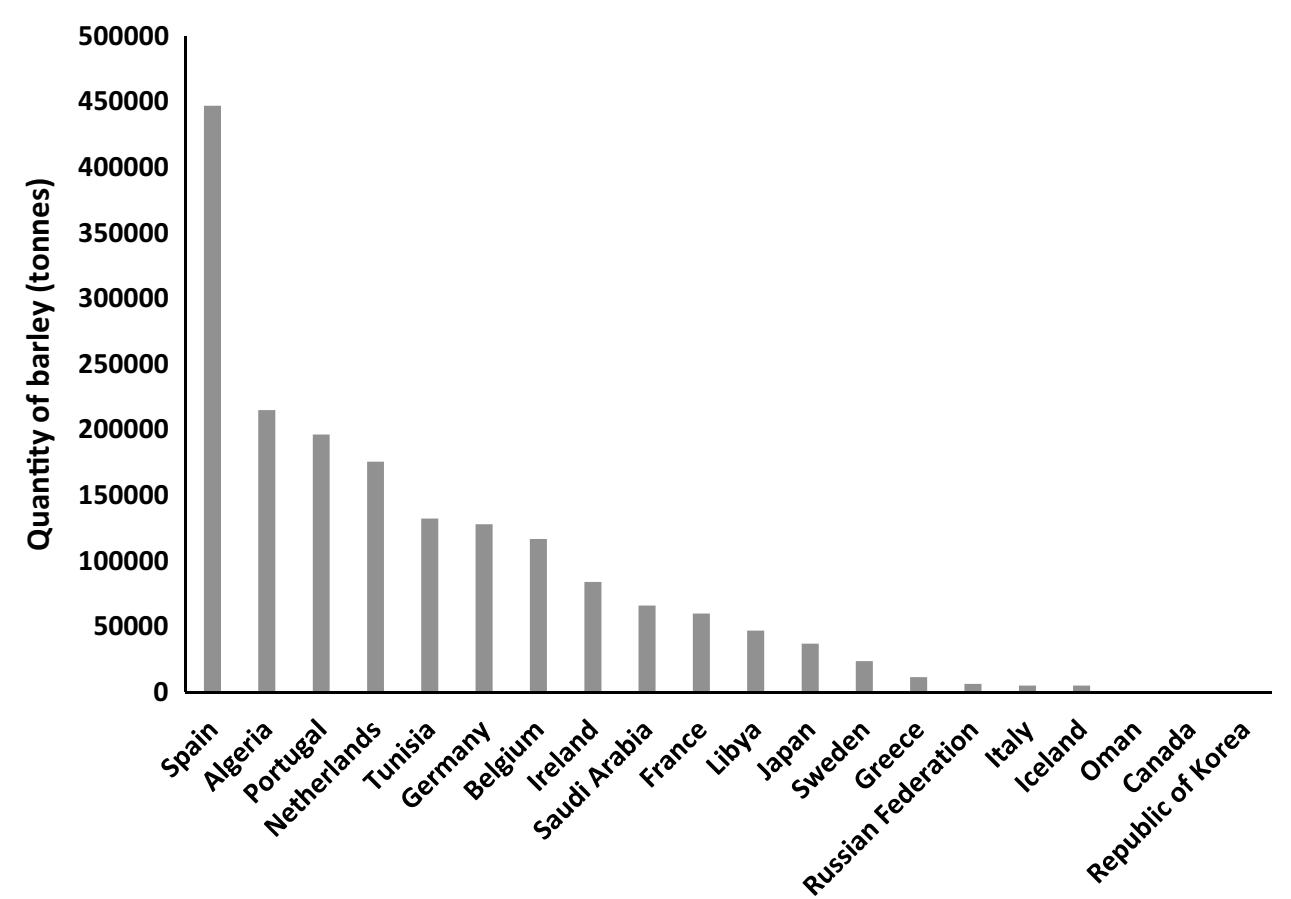




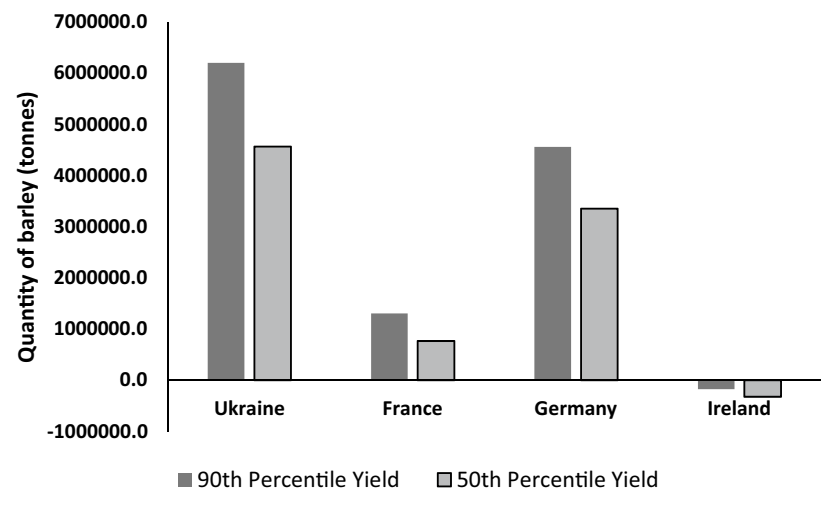

Fig. 7 Exportable fraction of barley (surplus over domestic demand that can potentially be exported) in the UK's main sources of barley imports in the 2050s

with Ireland remaining the top exporting country to the UK.

Ukraine and Germany had the largest exportable fraction after accounting for domestic demand (Fig. 7). At 90th percentile yield, the exportable fraction for Ukraine and Germany were about 6.2 and 4.6 million tonnes, respectively. Ireland (UK's main source of barley) had negative exportable fraction, indicating excess demand over supply (as its current supply for domestic use was 179\% of total production, implying considerable import and re-export). The future exportable fraction of Ireland and France, at both 90th and 50th percentile yields, were lower than the current total export but the reverse was true for Germany (Table 5). Ukraine's future exportable fraction was larger than current export at 90 th percentile yield but not at 50 th percentile yield. After accounting for the share of export to the top 20 importers from the exportable fraction, the remaining quantity (residual) was generally insufficient to meet the expected share of export to satisfy the UK deficit. It is noteworthy that the estimates of future production and demand were based on current land area and per capita supply, respectively.

\section{Discussion}

\subsection{Mitigation policies, land use change and UK deficits}

Climate change presents enormous existential and development burdens to humanity. Despite some scepticism, effort to tackle climate change has gained traction recently. The Paris Agreement and the Sustainable Development Goal 13 have given fresh impetus to taking extraordinary measures in the interest of climate change mitigation and adaptation. However, land-based climate mitigation efforts could have adverse, unintended consequences for food security through changes in land use. The current study assessed the effect of the updated study on UK land-based climate mitigation scenarios, in combination with projected climate and population change on the balance of demand and supply of feed barley or feed barley equivalent meat (FBEM) in the UK in the 2030s, 2040s and the 2050s. Generally, climate change alone would benefit UK barley yields as the projected yields increased from the low emissions scenario (LES) to the high emissions scenario (HES) and from the 2030s to the 2050s (Fig. 1) and over baseline yields for all emissions scenarios and time slices, indicating viability of UK barley production in the future [15]. This implies a HES gives the UK the greatest yield gain across the time slices, making the UK a climate-beneficiary country with respect to barley production.

While yield increases would be a major determinant of future supply of food from crops [3], total land area allocated to agriculture would be equally an important determinant of adequate supply of food. Notwithstanding the potential beneficial effect of climate change, the results in the current study show that total UK barley production (or supply) would substantially lag behind demand if projected reductions in land area for agriculture arising from land-based climate mitigation policies or efforts materialize. For all the climate mitigation land use scenarios and time slices, the total land area for barley production is less
Table 5 Estimated future barley supply and balances in the main countries from which the UK imports barley

\begin{tabular}{|c|c|c|c|c|c|c|c|c|}
\hline \multirow[t]{2}{*}{ Partner country } & \multicolumn{2}{|c|}{$\begin{array}{l}\text { (Future - current) total } \\
\text { export (tonnes) }\end{array}$} & \multicolumn{2}{|c|}{$\begin{array}{l}\text { Share of export to top } \\
20 \text { importers (tonnes) }\end{array}$} & \multicolumn{2}{|c|}{$\begin{array}{l}\text { Residual for } \\
\text { export to other } \\
\text { countries } \\
\text { (tonnes) }\end{array}$} & \multicolumn{2}{|c|}{$\begin{array}{l}\text { Expected } \\
\text { export as } \\
\text { proportion } \\
\text { of UK deficit } \\
\text { ('000 tonnes) }\end{array}$} \\
\hline & 90th & 50th & 90th & 50th & 90th & 50th & 90th & 50th \\
\hline Ireland & $-203,798$ & $-352,648$ & - & - & - & - & 3742 & 3874 \\
\hline France & $-4,561,573$ & $-5,100,943$ & $1,287,101$ & 755,822 & 19,601 & 11,510 & 1354 & 1401 \\
\hline Germany & $1,661,237$ & 457,397 & $4,556,028$ & $3,353,031$ & 3191 & 2349 & 1035 & 1072 \\
\hline Ukraine & $1,403,106$ & $-235,476$ & $6,106,764$ & $4,494,072$ & 98,036 & 72,146 & 557 & 577 \\
\hline
\end{tabular}


than the average land area currently under production (the BAU, Fig. 2) and the land area under the Mid-scenario (equivalent to the Central Scenario in the current study) in the 2030s in the previous report of Thomson et al. [36]. As a result, even at 90th percentile yields, deficits in both feed barley and FBEM in the current study are larger than those reported previously [16]. In the current study, the observed increase in cropland area across the time slices for all the land use scenarios (Fig. 2) implies more stringent mitigation efforts in the short term, with gradual relaxation in the medium to long term. However, the increase in land area due to the progressive relaxation of the mitigation efforts, in combination with the observed yield increase, is not sufficient to significantly reduce the deficits even in the 2050s where the highest yields occur under the HES. In addition, the comparatively lower land areas under the BL and the Low land use scenarios imply much larger deficits in the future if either current or stringent emission reduction pathways are followed. Because the revised land use scenarios embody current climate policy aspirations and activities, as well as updated greenhouse gas inventory data, the projected deficits in the current study show potential food penalties that can be incurred as a result of land-based mitigation policies in the UK. The plausibility of future reductions in cropland area in the UK derives from the fact that, historically, agricultural land use change in the UK has been driven primarily by government policy intervention, with other factors such as farm incomes, prices and land values playing secondary roles $[2,42]$. It is likely, therefore, that there will be reductions in the area of UK croplands (and possibly for barley) in future due to policies regarding climate change and energy. For example, Rowe et al. [43] reported that, to meet projected energy targets, between 2.7 and 7.0 Mha of land would be required for bioenergy production in the UK by 2050 .

Feed barley is the largest source of coarse grain used as animal feed in the UK and the world, and the straw, which has a higher feed value than that of wheat, is also used as a source of roughage in animal feed rations. Currently, the UK has high self-sufficiency rate in barley production, with export exceeding import (Fig. 6; [16]). Total import from the baseline Food Balance Sheet (FBS) was 115 thousand tonnes and total import in 2016 was about $6 \%$ of total export. According to FAOSTAT, the UK was the 7th largest producer and the 6th largest exporter of barley in the world in 2017. Based on the Central land use scenario of the climate mitigation policies, and at a 90th percentile yield under the medium emission scenario (MES), the UK moves from a net exporter to a potentially net importer of barley of approximately 7.1, 7.5, and 8.0 million tonnes for the 2030s, 2040s and 2050s, respectively, all being larger than total production in 2018 (6.5 million tonnes). These figures are even higher under the BL climate mitigation land use scenario. To bridge this deficit, barley area needs to increase by over one million ha by 2050 if yields do not increase substantially above those observed in this study. Meat is a major source of calories in the UK diet. According to the baseline FBS, meat consumption per capita in the UK was $84.2 \mathrm{~kg}_{\text {year }}{ }^{-1}$, delivering $457 \mathrm{kcal} \mathrm{cap}^{-1}$ day $^{-1}$. It is also a major source of not only protein but also essential micronutrients. As a result, meat production is crucial to food security in the UK, at least from the perspective of supplying the needed calories and nutrition, as well as food safety. The UK is a major producer of poultry meat and the largest producer of sheep and goat in the EU at the time of this study. Although the UK is currently a net importer of meat, it is clear that domestic meat production is crucial to its food security. Domestic meat production relies heavily on domestic feed barley supply as the production of other coarse grains, such as corn, is limited. The result in the current study show that pursuit of the land-based climate mitigation policy scenarios can result in substantial feed barley deficits, which, in turn, results in correspondingly large deficits in FBEM. Under the Central land use scenario, deficits in FBEM ranged from 1719.29 thousand tonnes (HES, 2030) to 2106.68 thousand tonnes (LES, 2050s). The deficits in the current study are observed against the backdrop of very marginal increase in per capita meat demand across the time slices as shown in the methods section, suggesting population growth will be the main driver of demand.

In spite of increasing health concerns, the consumption of meat and animal products are projected to rise to the 2050s not only due to population growth but also the rich supply of high value proteins and essential micronutrients [2]. In high-income countries such as the UK, the increase in demand will mostly be driven by population growth while higher disposable incomes would drive meat consumption in low- and middle-income countries [1]. It is acknowledged that feed requirements and use efficiencies differ among animals. Hence, differences in the proportions of different meat demand might alter the total quantity of feed barley demand and, for that matter the result of the current study. For example, it has been observed that the per capita consumption of beef is reducing while poultry and pig meats are fast becoming the preferred meat in the UK (Defra, 2011) and the EU [44], and poultry has higher feed conversion efficiency than beef cattle. However, the shift from beef and lamb to poultry and pig is attributed to the relatively higher cost per unit mass of beef or lamb and the shift towards poultry and pig might change with improvements in the economy [44]. Increasing cost of feed (mainly cereal grains) has been a major driver of increasing cost of animal production and, by extension, prices of meat in the UK (Defra, 2011). Considering that, currently, the EU and the UK use 54\% and 
$52 \%$, respectively, of total grains produced for feed $[2,3]$, the continuous and increased domestic production of feed barley is critical to UK meat production and food security (local availability and economic access to consumers). In addition to the large deficits observed in the current study, projections suggest that meat and animal feed import to the EU will increase substantially in the future $[3,44]$. The EU is currently the main trading partner of the UK in terms of meat and feed grains. Faced with large deficits, and all things being equal, the UK would import barley or FBEM to balance the deficits. Given the projected situation in the EU and with Brexit on the horizon, it is important to contemplate where all this import of barley or FBEM will come from to balance the observed deficits.

\subsection{Implications for national and transnational food security}

Food security can be defined as the "risk of adequate food not being available" [45]. Food here refers to meat (undergirded by feed barley). Proceeding from this definition, and in the light of the discussion above, the projected deficits in feed barley and FBEM in the current study, as a result of reductions in croplands in response to landbased climate mitigation policies, raise risks of future food insecurity in the UK with transnational consequences. Meat consumption delivers a substantial fraction of total calories and essential micronutrients in the UK and the world. Shifts from meat consumption to vegetarian diets are being promoted for health and environmental reasons (e.g. [46]). While this shift can reduce meat demand, meat consumption would remain an important part of diets in the near term. Here, we used CLD and analysis of the current barley imports by the UK and estimates of future supplies in its main sources of imports as a microcase to explore the implications of the observed deficits in the UK for national and transnational food security.

According to the FAOSTAT, the UK remains one of the top 10 barley exporters in the world. The analysis of the UK imports confirmed that the UK is a small importer of barley and mainly from Ireland (Fig. 5). However, the UK imports could increase considerably in the future as deficits under all climate mitigation scenarios could be as high as 53\% of total demand in the 2050s while FBEM could exceed $70 \%$ of total demand. At the same time, the exportable fraction of some of its main partners would be lower than current total export at both 90th and 50th percentile yields (Table 5). Ireland (the main source of UK's import) could have negative balance for export after serving domestic demand. As a result, the expected future imports by the UK would have to come from France, Germany and Ukraine where adjustments in the trade flows to their top importing countries would be necessary to accommodate the increased imports from the UK. Otherwise, the residual exportable fraction would not be adequate to meet their respective proportionate exports expected to address the observed deficits in the UK. At 90th percentile yield, the expected proportionate imports from Ukraine, Germany and France to satisfy the observed deficit under the MES in the 2050s (Table 5) would be approximately $9 \%$, $23 \%, 104 \%$, respectively, of the exportable fractions. The corresponding values at 50th percentile yield would be approximately $13 \%, 32 \%, 183 \%$, respectively. This suggests considerable pressure on the proportionate distribution of exports from these countries.

The top 20 importers of these countries include a number of developing countries in North Africa and Middle East where climate change would have strong adverse effects on agriculture. According to FAOSTAT, developing countries currently among the top ten barley importers in the world are Saudi Arabia, China, Iran, Morocco, and Jordan. Major destinations of UK barley exports include Algeria, Tunisia and Saudi Arabia. These countries feature strongly on the top importing country lists for France, Germany, and Ukraine. In the Islamic countries, feed barley could be crucial for animal production as it is perhaps difficult to import frozen or processed meat from many countries due to religious considerations (e.g. halal and slaughtering of live animals for special ceremonies).

Currently, Africa and Asia have the lowest self-sufficiency rates, and Africa accounts for about $50 \%$ of direct consumption of barley as food [4]. Previous studies have highlighted the potential adverse impacts of climate mitigation policies on global or regional food security (e.g. [18, $19,21,23,25])$. Africa and Asia were observed to suffer the greatest effects of food insecurity due to global stringent climate mitigation policies $[20,23]$ or climate impacts on vulnerability to food insecurity [25] or poor combination of mitigation and adaptation [18]. Due to the UK's strong position as a producer and exporter in the world, together with the EU, it is obvious that any reduction in production and increase in demand or import would likely intensify competition on the global market. The question is, can these developing countries compete effectively with the developed, strong trading nations, such as the UK in a tight global market of barley? The results in the current study, therefore, provides a basis for a nuanced understanding of the impacts of land-based climate mitigation policies or efforts on the food security of the UK and potential telecoupled impacts on other distal economies. Meaning, the UK (as a climate-beneficiary country with regard to barley) should make efforts to sustain higher capacity for barley production to serve the climate justice principle of 'equitable sharing of benefits and burdens'. 


\subsection{Assumptions and limitations}

This paper is based on several assumptions and semiempirical relationships between current and future production and feed use of barley that have implications for the results. For example, feed use as a proportion of total barley production and in meat production is neither linear nor constant. In other words, it is not deterministic. This key assumption is a limitation to the study but is one of the very few possibilities for doing such work. Policy, economic, social, and biophysical factors could alter the proportion of barley used for feed, or the composition of barley in total feed. More so, the total UK barley production is a sum of the product of winter and spring barley yields and their respective land areas. Winter barley has a higher yield than spring barley; but spring barley covers a larger area than winter barley. The current study is based on spring barley, assuming that the relatively larger area under spring barley production would compensate for the relatively higher yield of winter barley. In addition, future yields could be increased through technology (e.g. improvements in genotypes and agronomic practices) but this was not considered in the current study. While technology-driven increase in yields is feasible, it is difficult to predict. Brisson et al. [47] observed that cereal yields seem to have plateaued in Europe and sought to explain why this is the case for wheat yields. By extension, it is possible that barley yields could be substantially increased through technology if some of the identified constraints are addressed. For example, in the current study, it was observed that if future barley yields reach 10 tons ha ${ }^{-1}$ or higher, together with the current land area (BAU), the observed deficits can be reduced significantly or neutralized with a little increase over the current land area (BAU). This magnitude of yield has been observed for the genotype Westminster under experimental conditions at the James Hutton Institute (Dundee, UK). Since the mid-1980s, declines in areas of croplands in high-income countries have been more than compensated for by productivity gains per unit area and very intensive use of land $[1,48]$. The question is whether this trend can continue to the 2050 s given the observed plateau in cereal yields. Similarly, there is considerable scope for improving feed conversion efficiencies of animals (e.g. carcass yield per unit feed) and effecting changes in the composition of meat consumption. These could alter the scale of deficits in the current study. However, as with any projection study, the key message from the current study shows a future possibility within the bounds of the assumptions and limitations of the study. Finally, estimates of future demand and supply in the UK's main trading partner countries were based on current consumption and linear relationship between their yields and the UK yields, respectively. The scale of demand and exportable fraction in these countries could be altered by a more detailed study of the combined impacts of climate, population, and land use changes in these countries.

\section{Conclusions}

Climate change mitigation is a global desideratum. However, land-based climate change mitigation policies or efforts should be carefully designed and analysed to minimize unintended adverse consequences. The current study supports, at a detailed spatial scale, the emerging concern that land-based climate mitigation policies could adversely affect food security. While climate change alone could be beneficial to UK barley production, projected reductions in cropland areas due to land-based climate mitigation policies can combine with increased demand due to population growth to create large deficits in feed barley supply from domestic production. Because feed barley accounts for the largest share of coarse grain used in animal feed, the observed deficits would create correspondingly large deficits in feed barley equivalent meat (FBEM) supply. The situation would be worse if projected median yields are observed. This risk of inadequate supply of meat would have adverse implications for the UK food security as meat is an important source of daily calories, high value protein and essential micro-nutrients. The study demonstrates how a combination of climate change, climate mitigation policies, and population growth can impact on feed barley and meat supply in the future and the need to develop measures to effectively manage the demand and supply sides of feed barley and meat. Because the UK is a strong trading nation and, currently, a major exporter of barley, the prospect of the UK sourcing feed barley or meat from the global market is a case that highlights the potential for high-income countries with high capacity for barley and meat production (such as in the EU) turning to compete intensely with developing countries in the global market. Such intensification of competition on the global market due to supply deficits in major producing countries could make it harder for poor countries to economically access feed barley and/or meat, and therefore adversely affect their food security. It is suggested that a global cooperation around land use is necessary to address the complex issues in the nexus of climate mitigation and food security while paying special attention to the implications for developing economies. This is to ensure that global capacity for certain key crops such as barley is not compromised to exacerbate food insecurity much beyond the net effect of climate change alone or the national scale. 
Funding This study was part of a PhD work sponsored by the Centre for Environmental Change and Human Resilience (CECHR, University of Dundee), The James Hutton Institute (Scotland), and the University of Cape Coast (Ghana).

\section{Compliance with ethical standards}

Conflict of interest The authors declare that they have no conflict of interest.

\section{Appendix 1}

See Table 6.

Table 6 Soil hydraulic properties from the SINFO database used in the simulations

\begin{tabular}{lllllll}
\hline $\begin{array}{l}\text { Admin. sub- } \\
\text { region }\end{array}$ & Dominant soil & $\theta_{\text {sat }}$ & $\theta_{\text {pwp }}$ & $\theta_{\mathrm{fc}}$ & $\begin{array}{l}\text { Rooting depth } \\
(\mathrm{m})\end{array}$ & $\theta_{\text {asw }}\left(\mathrm{mm} \mathrm{m}^{-1}\right)$ \\
\hline EE & Medium & 0.42 & 0.18 & 0.33 & 7 & 150 \\
EM & Fine & 0.49 & 0.29 & 0.43 & 6.8 & 140 \\
NI & Medium & 0.41 & 0.16 & 0.31 & 6.6 & 150 \\
NEE & Medium & 0.42 & 0.18 & 0.34 & 6.6 & 160 \\
NES & Medium & 0.41 & 0.15 & 0.30 & 6.1 & 150 \\
NWE & Medium & 0.43 & 0.19 & 0.34 & 6.4 & 150 \\
NWS & Medium & 0.40 & 0.15 & 0.29 & 7.0 & 140 \\
SEE & Medium fine & 0.55 & 0.14 & 0.49 & 5.9 & 350 \\
SES & Medium & 0.41 & 0.15 & 0.32 & 6.2 & 170 \\
SWE & Medium fine & 0.58 & 0.15 & 0.50 & 4.4 & 350 \\
SWS & Medium & 0.41 & 0.15 & 0.31 & 6.4 & 160 \\
WA & Medium & 0.45 & 0.22 & 0.37 & 6.9 & 150 \\
WM & Medium & 0.45 & 0.22 & 0.37 & 6.7 & 150 \\
YH & Medium & 0.43 & 0.19 & 0.35 & 6.5 & 160 \\
\hline
\end{tabular}

Data taken from the SINFO database [29] 


\section{Appendix 2}

\section{See Table 7.}

Table 7 Main AquaCrop parameters used in the climate change simulations

\begin{tabular}{|c|c|c|}
\hline Symbol & Parameter description & Value \\
\hline \multicolumn{3}{|c|}{ 1. Crop phenology } \\
\hline \multicolumn{3}{|c|}{ 1.1. Development of green canopy cover (CC) } \\
\hline & Initial canopy cover (\%) & 3.6 \\
\hline & Time from sowing to emergence (GDD) & 135 \\
\hline & Canopy growth coefficient (fraction per GDD) & 0.8 \\
\hline & Maximum canopy cover (\%) & 85 \\
\hline & Time from sowing to flowering (GDD) & 950 \\
\hline & Length of flowering stage (GDD) & 215 \\
\hline & Time from sowing to start of senescence (GDD) & 1315 \\
\hline & Canopy decline coefficient (fraction per GDD) & 0.06 \\
\hline & Time from sowing to maturity (GDD) & 1675 \\
\hline \multicolumn{3}{|c|}{ 1.2. Development of root zone } \\
\hline & Minimum effective rooting depth (m) & 0.30 \\
\hline & Maximum effective rooting depth (m) & 0.70 \\
\hline & Shape factor describing root zone expansion & 1.5 \\
\hline \multicolumn{3}{|c|}{ 2. Crop Transpiration } \\
\hline & Crop coefficient at maximum CC & 1.15 \\
\hline & Decline of crop coefficient $\left(\%\right.$ day $\left.^{-1}\right)$ due to ageing & 0.15 \\
\hline & Effect of canopy shelter on surface evaporation in late season stage (\%) & 50 \\
\hline \multicolumn{3}{|c|}{ 3. Biomass production and yield formation } \\
\hline \multicolumn{3}{|c|}{ 3.1. Crop water productivity } \\
\hline \multirow[t]{2}{*}{$W P^{*}$} & Water productivity normalized for $\mathrm{ET}_{\mathrm{O}}$ and $\mathrm{CO}_{2}\left(\mathrm{~g} \mathrm{~m}^{-2}\right)$ & 15 \\
\hline & $\begin{array}{l}\text { Water productivity normalized for } \mathrm{ET}_{\mathrm{O}} \text { and } \mathrm{CO}_{2} \text { during yield formation (as } \% \mathrm{WP} * \text { before yield } \\
\text { formation) }\end{array}$ & 100 \\
\hline \multicolumn{3}{|c|}{ 3.2. Harvest index $(\mathrm{HI})$} \\
\hline & Reference harvest index (Hlo) & 0.49 \\
\hline & Upper threshold for water stress during flowering on $\mathrm{HI}$ & 0.82 \\
\hline & Possible increase (\%) of $\mathrm{HI}$ due to water stress before flowering & 12 (strong) \\
\hline & Coefficient describing positive effect of restricted vegetative growth during yield formation on $\mathrm{HI}$ & Moderate \\
\hline & Coefficient describing negative effect of stomatal closure during yield formation on $\mathrm{HI}$ & Moderate \\
\hline & Excess of potential fruits & Moderate \\
\hline & Allowable maximum increase (\%) of specified $\mathrm{HI}$ & 15 \\
\hline \multicolumn{3}{|c|}{ 4. Stresses } \\
\hline \multicolumn{3}{|c|}{ 4.1. Soil water stress } \\
\hline$P_{\text {exp,lower }}$ & Lower threshold of water stress for triggering inhibited canopy expansion & 0.60 \\
\hline \multirow[t]{2}{*}{$P_{\text {exp,upper }}$} & Upper threshold for canopy expansion (canopy expansion seizes) & 0.27 \\
\hline & Shape factor for water stress coefficient for canopy expansion & 3.5 \\
\hline \multirow[t]{2}{*}{$P_{\text {sto }}$} & Upper threshold for stomata closure & 0.60 \\
\hline & Shape factor for water stress coefficient for stomatal control & 3.0 \\
\hline \multirow[t]{2}{*}{$P_{\text {sen }}$} & Upper threshold for early senescence due to water stress & 0.60 \\
\hline & Shape factor for water stress coefficient for canopy senescence & 3.5 \\
\hline \multirow[t]{2}{*}{$P_{\text {pol }}$} & Upper threshold of soil water depletion for failure of pollination & 0.80 \\
\hline & Vol\% at anaerobiotic point (with reference to saturation) & 15 \\
\hline \multicolumn{3}{|c|}{ 4.2. Temperature stress } \\
\hline & Minimum air temperature below which pollination starts to fail (cold stress, ${ }^{\circ} \mathrm{C}$ ) & 5 \\
\hline & Maximum air temperature above which pollination starts to fail (heat stress, ${ }^{\circ} \mathrm{C}$ ) & 30 \\
\hline & Minimum growing degrees required for full biomass production $\left({ }^{\circ} \mathrm{C}\right.$ day $\left.{ }^{-1}\right)$ & 15 \\
\hline
\end{tabular}




\section{Appendix 3}

See Fig. 8.

Fig. 8 Projected barley grain yield for the low, medium, high emission scenarios (LES, MES, and $H E S$, respectively) in the 2040s, 2050s, and the 2050s

\section{Appendix 4}

See Fig. 9.

Fig. 9 Projected land area for barley in 2030, 2040, and 2050 based on climate mitigation policies [34]. The total area of barley under the BAU remains constant at 1026 thousand ha from 2030 to 2050

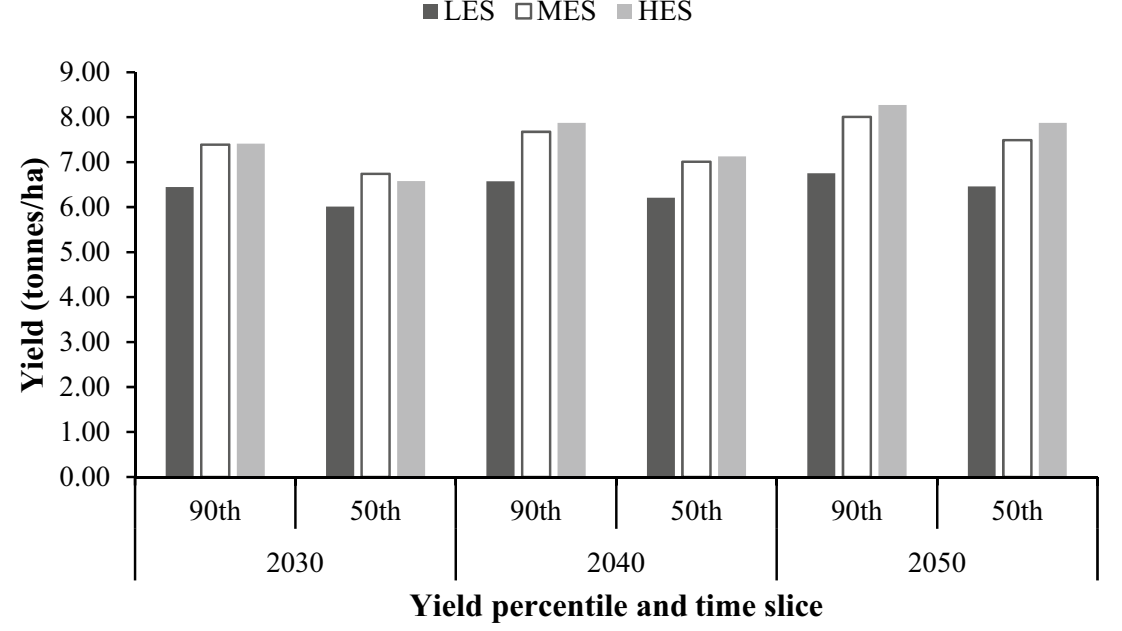

Yield percentile and time slice 


\section{Appendix 5}

See Fig. 10.

Fig. 10 Projected feed barley and feed barley equivalent meat demand

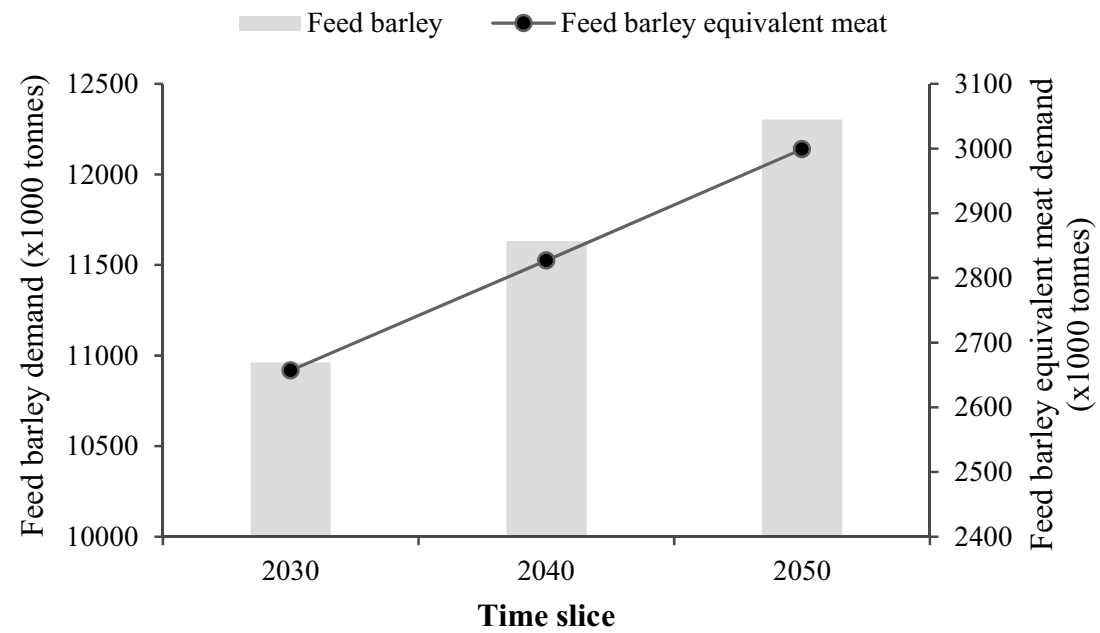

10. Clausen SK, Frenck G, Linden LG, Mikkelsen TN, Lunde C, Jørgensen RB (2011) Effects of single and multifactor treatments with elevated temperature, $\mathrm{CO}_{2}$ and ozone on oilseed rape and barley. J Agron Crop Sci 197:442-453

1. Alexandratos N, Bruinsma J (2012) World agriculture towards 2030/2050: The 2012 revision. ESA working paper, no. 12-03. Food and Agriculture Organization, Rome, Italy

2. Foresight (2011) The future of food and farming: challenges and choices for global sustainability. Final project report, The Government Office for Science, London, UK

3. Bruinsma J (2012) European and Central Asian agriculture towards 2030 and 2050. Policy studies on rural transition no. 2012-1. FAO Regional Office for Europe and Central Asia, Rome, Italy

4. Newton AC, Flavell AJ, George TS, Leat P, Mulholland B, Ramsay L, Revoredo-Giha C, Russell J, Steffenson BJ, Swanston JS et al (2011) Crops that feed the world 4. Barley: a resilient crop? Strengths and weaknesses in the context of food security. Food Secur 3:141-178

5. Kruse J (2011) Estimating demand for agricultural commodities to 2050; report no. 3-16-10; Global Harvest Initiative: Washington, DC, USA. http://www.globalharvestinitiative.org/Docum ents/Kruse $\% 20-\% 20$ Demand\%20for\%20Agricultural\%20Com moditites.pdf. Accessed 23 July 2013

6. DaMatta FM, Grandis A, Arenque BC, Buckeridge MS (2010) Impacts of climate change on crop physiology and food quality. Food Res Int 43:1814-1823

7. Richter GM, Semenov MA (2005) Modelling impacts of climate change on wheat yields in England and Wales: assessing drought risks. Agric Syst 84:77-97

8. Rötter RP, Palosuo T, Pirttioja NK, Dubrovsky M, Salo T, Fronzek S, Aikasalo R, Trnka M, Ristolainen A, Carter TR (2011) What would happen to barley production in Finland if global warming exceeded $4{ }^{\circ} \mathrm{C}$ ? A model-based assessment. Eur J Agron 35:205-214

9. Claesson J, Nycander J (2013) Combined effects of global warming and increased $\mathrm{CO}_{2}$-concentration on vegetation growth in water-limited conditions. Ecol Model 256:23-30
11. Manderscheid R, Pacholski A, Frühauf C, Weigel H-J (2009) Effects of free air carbon dioxide enrichment and nitrogen supply on growth and yield of winter barley cultivated in a crop rotation. Field Crops Res 119:185-196

12. Fangmeier $A$, Chrost $B$, Högy $P$, Krupinska $\mathrm{K}$ (2000) $\mathrm{CO}_{2}$ enrichment enhances flag leaf senescence in barley due to greater grain nitrogen sink capacity. Environ Exp Bot 44:151-164

13. Holden NM, Brereton AJ, Fealy R, Sweeney J (2003) Possible change in Irish climate and its impact on barley and potato yields. Agric For Meteorol 116:181-196

14. Robredo A, Pérez-López U, Miranda-Apodaca J, Lacuesta $M$, Mena-Petite A, Muñoz Rueda A (2011) Elevated $\mathrm{CO}_{2}$ reduces the drought effect on nitrogen metabolism in barley plants during drought and subsequent recovery. Environ Exp Bot 71:399-408

15. Yawson DO, Ball T, Adu MO, Mohan S, Mulholland BJ, White PJ (2016) Simulated regional yields of spring barley in the United Kingdom under projected climate change. Climate 2016(4):54

16. Yawson DO, Mulholland BJ, Ball T, Adu MO, Mohan S, White PJ (2017) Effect of climate and agricultural land use changes on UK feed barley production and food security to the 2050s. Land 2017(6):74. https://doi.org/10.3390/land6040074

17. FAO (2008) Climate change and food security: a framework document. Food and Agriculture Organization of the United Nations, Rome

18. Richardson KJ, Lewis KH, Krishnamurthy PK, Kent C, Wiltshire AJ, Hanlon HM (2018) Food security outcomes under a changing climate: impacts of mitigation and adaptation on vulnerability to food insecurity. Clim Change 147:327-341

19. Fischer $G$ (2011) How can climate change and the development of bioenergy alter the long-term outlook for food and agriculture?. FAO, Rome, pp 95-155

20. Hasegawa T, Fujimori S, Shin Y, Tanaka A, Takahashi K, Masui T (2015) Consequence of climate mitigation on the risk of hunger. 
Environ Sci Technol 49(12):7245-7253. https://doi.org/10.1021/ es5051748

21. Nelson GC, Rosegrant MW, Amanda P, Gray I, Ingersoll C, Robertson R, Tokgoz S, Zhu T, Sulser TB, Ringler C, Msangi S, You $L$ (2010) Food security, farming, and climate change to 2050: scenarios, results and policy options. IFPRI, Washington

22. Parry M, Rosenzweig C, Livermore M (2005) Climate change, global food supply and risk of hunger. Philos Trans R Soc Lond Ser B 360(1463):2125-2138

23. Hasegawa T, Fujimoro S, Havlik P et al (2018) Risk of increased food insecurity under stringent global climate change mitigation policy. Nat Clim Change 8:699-703

24. Popp A, Calvin K, Fujimori S et al (2017) Land-use futures in the shared socio-economic pathways. Glob Environ Change 42:331-345

25. Krishnamurthy PK, Lewis K, Choularton RJ (2014) A methodological framework for rapidly assessing the impacts of climate risk on national-level food security through a vulnerability index. Glob Environ Change 25:121-132

26. Murphy JM, Sexton DMH, Jenkins GJ, Booth BB, Brown CC, Clark RT, Collins M, Harris GR, Kendon EJ, Betts RA et al (2009) UK climate projections science report: climate change projections. Met Office Hadley Centre, Exeter, p 2009

27. Jones PD, Kilsby CG, Harpham C, Glenis V, Burton A (2009) UK climate projections science report: projections of future daily climate for the UK from the weather generator. University of Newcastle, Newcastle, p 2009

28. Lowe JA, Bernie D, Bett P, Bricheno L et al (2019) UKCP18 science overview report (version 2, updated March 2019). Met Office, UK. https://www.metoffice.gov.uk/pub/data/weather/uk/ukcp1 8/science-reports/UKCP18-Overview-report.pdf. Accessed 07 Aug 2019

29. Baruth B, Genovese G, Montanarella L (2006) New soil information for the MARS crop yield forecasting system. European Commission Directorate General, Joint Research Centre, Ispra, Italy

30. Raes D, Steduto P, Hsiao TC, Fereres E (2009) AquaCrop-the FAO crop model to simulate yield response to water: II. Main algorithms and software description. Agron J 101:438-447

31. Steduto P, Hsiao TC, Raes D, Fereres E (2009) AquaCrop-the FAO crop model to simulate yield response to water: I. Concepts and underlying principles. Agron J 101:426-437

32. Yawson DO (2013) Climate change and virtual water: implications for UK food security. PhD thesis, University of Dundee, UK

33. Mainuddin M, Kirby M, Hoanh CT (2011) Adaptation to climate change for food security in the lower Mekong Basin. Food Secur 3:433-450

34. Thomson A, Buys G, Moxley J, Malcolm H, Henshall P, Broadmeadow M (2017) Projections of emissions and removals from the LULUCF sector to 2050. Contract report prepared as part of the contract, Inventory and Projections of UK Emissions by Sources and Removals by Sinks due to Land Use, Land-Use Change and Forestry (LULUCF)

35. Climate Change Act (2008) Climate change act: 2008 chapter 27. An act of the UK Parliament. http://www.legislation.gov. uk/ukpga/2008/27/pdfs/ukpga_20080027_en.pdf. Accessed 07 Aug 2019
36. Thomson A, Hallsworth S, Malcolm H (2013) Projections of emissions and removals from the UK LULUCF sector to 2050; contract report prepared for the Department of Energy and Climate Change (DECC) as Part of the Contract Inventory and Projections of UK Emissions by Sources and Removals by Sinks due to Land Use, Land-Use Change and Forestry (LULUCF); Centre for Ecology and Hydrology: Bailrigg, UK, 2013; p. 28. http://uk-air. defra.gov.uk/reports/cat07/1304300925_Projections_of_emiss ions_and_removals_from_the_LULUCF_sector_to_2050_2011i _UK-FINAL-VERSION.pdf. Accessed 27 July 2013

37. IWMI (2007) Water for food, water for life: a comprehensive assessment of water management in agriculture; Earthscan (London), The International Water Management Institute: Colombo, Sri Lanka

38. Tilman D, Balzer C, Hill J, Befort BL (2011) Global food demand and the sustainable intensification of agriculture. PNAS 108(50):20260-20264

39. Armah FA, Yawson DO, Yengoh GT, Odoi JO, Afrifa EKA (2010) Impact of floods on livelihoods and vulnerability of natural resource dependent communities in northern Ghana. Water 2:120-139

40. Olsson M-O, Sjöstedt G (eds) (2005) Systems approaches and their applications: examples from Sweden. Springer, New York

41. UN DESA (2019) World population prospects 2019. Online edition, Rev 1, United Nations, Department of Economic and Social Affairs, Population Division

42. Angus A, Burgess PJ, Morris J, Lingard J (2009) Agriculture and land use: demand for and supply of agricultural commodities, characteristics of the farming and food industries, and implications for land use in the UK. Land Use Policy 26S:S230-S242

43. Rowe RL, Street NR, Taylor G (2009) Identifying potential environmental impacts of large-scale deployment of dedicated bioenergy crops in the UK. Renew Sustain Energy Rev 13:271-290

44. EC (2011) Prospects for agricultural markets and income in the EU 2011-2020. European Commission, Directorate for Agriculture and Rural Development. http://ec.europa.eu/agriculture/ publi/caprep/prospects2011/fullrep_en.pdf. Accessed 7 Jan 2015

45. Chakraborty S, Newton AC (2011) Climate change, plant disease and food security: an overview. Plant Pathol 60:2-14

46. Springmann M, Wiebe K, Mason-D'Croz D, Sulser TB, Rayner M, Scarborough P (2018) Health and nutritional aspects of sustainable diet strategies and their association with environmental impacts: a global modelling analysis with country-level detail. Lancet Planet Health 2(10):e451-e461

47. Brisson N, Gate P, Gouache D, Charmet G, Oury F-X, Huard F (2010) Why are wheat yields stagnating in Europe? A comprehensive data analysis for France. Field Crops Res 119:201-212

48. Pollock C (2011) Food for thought: options for sustainable increases in agricultural production. In: Foresight (2011). Foresight project on global food and farming futures. Regional Case Study R1: the UK in the context of North-west Europe. Government Office for Science, UK

Publisher's Note Springer Nature remains neutral with regard to jurisdictional claims in published maps and institutional affiliations. 